\title{
The change of the modern women's clothing structural design of provincial road and applications
}

\author{
Feng $\operatorname{lin}^{1, a}$ \\ ${ }^{1}$ Jiangxi Institute of Fashion Technology, Jiangxi, Nanchang, 330201 \\ a170166172@qq.com
}

Keywords: Women's clothing; Structure design; Provincial highway; Innovation; application

\begin{abstract}
As the progress and development of The Times, people living standard unceasing enhancement, clothing is no longer just warm single attribute, it has multiple functions such as decoration, advocating personality, warm. In this social background, the apparel industry needs to constantly advancing with The Times, fashion designers, plate-making division will also face new challenges, only design fashion, novel clothing can satisfy the need of The Times, play its real value. This thesis chose the most common clothing structure decomposition method, provincial highway research is an important content, through literature research, market research, such as web search contrast method deeply explores the application of the dart in the clothing structure design and innovation.
\end{abstract}

\section{The introduction}

The human body is a complex forms, especially the women so much more complex structure of human body due to physiological changes. To make the garment worn on the human body has beauty must study the structure of the clothing processing method. To transfer the prototype, shearing, folding, such as deformation method, the provincial highway, pleat, smoke plait, split the province into a variety of ways, such as sewing certain structure processing, can create a shape. Clothing for three-dimensional processing a structure form of the most important is the provincial highway, it is an important means of human performance curve, provincial highway after the suture can make flat fabrics to form three-dimensional joint human body, especially in women's clothing in the bosom, waist, hip. So on the garment to meet the requirements of joint human body must be used dart.

\section{The concept of provincial highway and meaning}

Sheet in the plane of the province is the joint to the human body surface rolling shape after clipping, in order to get clothing modelling outline curve effect, is essentially a way of sewing clothes. Can make human body sag area to get rid of excess fabric, and can make the garment table bulge and accommodate a convex body, to conform to the surface, the purpose of the modified size.

Province the advent of clothes on a gothic period became the intersection of ancient and modern, Chinese and western, provincial highway in clothing structure design is of great significance. It is because the provincial highway in the clever use of in the women's clothing structure design makes women's clothing to the human body curves show incisively and vividly. Provincial highway on women's clothing, for this is determined by the structure of the female body is complex and changeable, in human form, is concave and convex stereoscopic female human body. Clothing structure design to build up a three-dimensional modelling beautiful stick put oneself in the province on the clothing of transformation is particularly important. Female curve is more outstanding, therefore, flat cloth to sew into form-fitting costume, make it can be attached with a in the body of the different curve, it must do accept province processing in the appropriate place. And the processing of provincial highway to considering factors such as design, fabrics, design, especially the women's clothing, different women have different qualities, different clothing demand, so for the women's fashion designer should have unique insights, comprehensive consideration, only in this way can make a good dress. 


\section{The basic principle of the transfer and application of provincial road transformation}

Provincial highway design. In the form of provincial highway. Provincial highway in a variety of forms, in the actual operation, fashion designers have to according to the need of the modelling and the nature of fabrics. Pattern: the choice of provincial road form mainly depends on the choice of the human body, basically see clothes make effect and the human body joint, according to the human body joint degree of provincial highway form choice is the most important, because the clothing service object is the objective of people. In the specific operation in the design of avoid by all means mechanically sew all provincial road on both sides of shape into two straight stitches, but the designer must be based on objective body shape would dart seam on either side of the arc and slightly take provincial highway has size changes.

Different parts of the highway design. Different parts of the dart design has a certain law, but also has its certain flexibility. Its flexibility performance in different shape and different fabric all affect the different parts of the highway design. Such as chest province is more suitable for the chest a little flat in shape, but shoulder dispense is more suitable for chest relatively large size. In addition, different parts of the dart fit also can have the same effect. Province amount of design: design of determined by the size of the human body surface area. Dart design: no matter how dart can only aim at the highs of the human body protruding, irrespective of the location and shape of the province to change, this rule will not change, otherwise will not expected effect. To make the garment pieces in conformity with the human body surface, need to make corresponding provincial road in different parts of the body. Because a piece of clothing appear on multiple provincial highway, which not only affects the appearance of the clothes, will also spend too much time in the process of sewing clothes. So in the structural design to ensure that in does not affect the premise of modelling design group related provincial roads with garment seam instead of, this method is called the province into the seam. Another garment seam sewing method and back seam, side seam, etc., and the main types have owner. on back seam line, high back seam and the princess line, etc.

Provincial highway transformation of basic principles. Converted form gave birth to a new province of provincial roads, this time for a new province have strict requirements, general new province moral length is not equal to base the size of the provincial highway, otherwise it will cause adverse consequences. Main reason is the foundation provincial corresponds to the human body chest bumps, and chest bumps need regional, must demand a certain capacity. Generally based on the size of the garment sample on provincial road than the size of the provincial highway short roughly about $3 \mathrm{~cm}$ to $4 \mathrm{~cm}$, if you exceed the size range returned to make chest form a certain Angle, and to reflect female chest round and cause some difficulties.

The principle of chest high design is also very noticeable. If after transfer model on the basis of the provincial road do not connected with the location of the new highway, it should follow the principle of the chest high design to ensure the dart point is accurate, provincial highway two edges is equal, only this can ensure the accuracy of provincial highway transformation and perfection. Provincial highway transformation considering the overall situation, must want to ensure the overall balance of garment body, so the clothes before and after the transformation of the waist section line must demand to maintain the same level as far as possible, otherwise it will affect the size accuracy and the overall balance of plate making, provincial highway deformation model in the cover of the fabric after cutting to comprehensive consider demand for textile fabric, in order to perfect.

\section{Provincial highway application in women's clothing structure design}

Bust dart design style. Chest is the most important parts of women's studies, because of its special physiological structure design of garment will produce many allowance, if bad design can cause chest do not conform with the human body, clothing will not be flat, this part are prone to fold. So bust dart design and must be based on morphology and full breasts. To some extent, the design style of chest province determines the style of the clothing modelling

High chest waist type: this kind of style is suitable for breast plump women, female chest waist of this kind of size difference is bigger, bust point position is low, the waist is fine. Design modelling to strengthen the effect of the waist, be waist province. Girl: this kind of style is suitable 
for puberty women, these women bust point distance is smaller, the chest high is higher, when designing clothing dart spacing should be larger, small amount of province and shaped like a cone shape. Elegant type: it is designed for flat chest of women, this kind of bodily form female breasts are relatively small and flat chest, intuitive point of view presents a female can't perfect curve, therefore when designing province amount to small and scattered. Flat-chested type: this kind of style is suitable for the women, flat-chested clothing not breast uplift pattern, the modelling of the waist and hips also relatively flat. Provincial highway design, the amount is small or not the province.

Provincial highway application methods and characteristics. It is because the shift makes provincial road to extend the use of technology, makes the ordinary form-fitting clothes again to make a variety of styles. Province all transfer refers to the amount of a garment on any part of the province is transferred to the same clothes, province amount unchanged, the number of the same, just according to the requirements of designers design area. Province transfer quantity decomposition is refers to the amount of decomposition is transferred to different parts of the paper, an equal amount of province, provincial number increase.

Draping designed mainly refer to female human body. Dart shift for the center with chest bumps. The most main is chest high as a benchmark to other provincial highway direction accordingly. In addition, the armhole province, shoulder, etc., can also follow this design principle combined with the design of bulge to transfer the dart. Province can transfer not only into position and quantity, the form can also be flexible change. Province after transfer to fold or to fly in the form of expression and the province of transfer operation is similar, only differ in structure, and the modelling of the final effect is also different. Province after conversion, shrink fold, fold amount will differ because of the provincial highway.

Province after the transformation in the form of a line as a performance, in does not affect the garment body fit, on the basis of the relevant province transferred to split position of the pieces, forming multiple forms. Women often use this method to design different styles of modelling, meet the needs of different temperament women on clothes. Special emphasis is province transfer component secant and transfer into new some different, provinces to transfer are on the same piece of prototype piece shift position, sheet is the whole piece type, and province chest high centered around basically radiated. Province transfer component secant, requires multiple split pieces according to the requirement of design. Such as body composition secant, common forms include the princess line, live line, tall waist line, etc. Down your back after province transfer can form the yoke.

Provincial highway form. The dart into the design method of pleat more common in women's T-shirt design, and the advantage is better than traditional straight T-shirt shape female bosom curve. Coat chest smoke plait can be decorated with cord and elastic fixation. Women's clothing line design is particularly important in women's clothing line contains the characteristics of women, women's clothing line with dart hiding technology combined with the form of the following:

Line design to dart position changes: line design is relatively flexible can even free, but if you want to carefully consider women's clothing modelling line design needs to be carefully read. Because if you want to the women's clothing line and dart hiding technology play together is more complicated, to achieve unity must request the lines in the design in the process of design need to be changed according to the location of the provincial highway. So how to make actual operation?

Combined with design can not be beyond the scope of female human body limit: model distinguish women on model basically see chest, waist, buttocks, provincial highway hidden was designed according to these three lines. Therefore needs to be done in combining with the characteristics of female body shape design. To the line as a standard, 3 provincial roads lengthened when not beyond the limit of hip line and line of the chest, and waist line is the part of the biggest clothing transverse province, therefore, the provincial highway and make waist line according to the requirement of the line is designed to raise or lower. Line and provincial roads should be the combination of design: can't exclude the ideal line when the dart design decorative design in highway hidden process, especially for women's clothing, if the lack of certain decorative clothing 
will seem boring and dull. So when the design can change by some interesting patterns, symbols in the design of on line.

In all provincial highway design is flexible, it is women's clothing design of the key factors for structural changes, design, reasonable combine lines and provincial road use. At the same time at the time of provincial highway design to flexible shift, random strain, want to think more, at the same time looking for the right transfer method, in order to achieve satisfactory result of highway design.

\section{Conclusion}

Provincial highway in the clothing structural design based on grasp the basic principles of the application must be flexible to use. Design is flexible, there is no uniform design. Clothing is a symbol of an era, every era of fashion designers have an obligation to give the connotation of the era, create belong to this era clothing, even to have a look to the future clothing ambitions. If clothing structure design in the specific design, in the service of human body, satisfied with the clothing modelling and the perfect unity of human body, on the basis of do snug fit to imagine constantly blaze new trails, create more style and dress styles, can rich clothing market, meet the consumers demand for modern dress.

\section{Reference}

[1] Yingxing Bian; Zhu Liu boat. Stereo dart in the women's garment body application [J] textile science and technology progress, 2014 (6) : 56-58.

[2] Dai Hong; Luo Rong. Ladies dart change and its application [J] journal of xi 'an engineering institute of technology, 2005 (3) : 23-27.

[3] Song Jing. Women's clothing design of provincial seam application research [D] the northeast normal university, 2010 (05). 